\title{
A Novel Soft-Switching Bidirectional DC-DC Converter for Dual Voltage Automotive Systems
}

\author{
V.V.Subrahmanya Kumar Bhajana ${ }^{1,2}$, Pavel Drabek ${ }^{2}$ \\ ${ }^{1}$ School of Electronics Engineering, KIIT University, Bhubaneswar, Odisha, India \\ ${ }^{2}$ Regional Innovation Centre for Electrical Engineering, University of West Bohemia, Pilsen, Czech Republic \\ kumarbvv@fel.zcu.cz, bvvs.kumarfet@kiit.ac.in,drabek@ieee.org
}

\begin{abstract}
This paper presents a new zero current switching bidirectional DC-DC converter for dual voltage automotive systems. The improved version of hard-switched DC-DC converter with an additional auxiliary resonant network, which is a combination of two auxiliary switches, two resonant inductors and two capacitors. The operating characteristics of this converter design is to transfer the power flow from low voltage to high voltage and vice-versa. The soft-turn on (ZCS) and soft-turn off (ZCS) operations are achieved by using two auxiliary resonant networks. In addition to that, the auxiliary switches obtain ZCS turn-on/ turn off operations, since additional losses are negligible. Minimized switching losses and improved efficiency are significant merits in this topology. The operation principles and design simulation analysis are reported in this paper in order to validate the theoretical analysis. The simulation of converter design is performed on $100 / 350 \mathrm{~V} / 500 \mathrm{~W}$ converter system operated at $75 \mathrm{kHz}$ switching frequency.
\end{abstract}

Keywords - Automotive systems; Boost converter; ZCS DCDC converter; Auxiliary resonant networks; Soft-switching DCDC converter.

\section{INTRODUCTION}

In recent trends, the power converters plays a major role in energy storage systems based on ultra-capacitors and fuel cells. In early days of research, to balance the battery voltages and reduce electromagnetic interference (EMI), a $14 \mathrm{~V} / 42 \mathrm{~V}$ magnetic less four level bidirectional converter [1] has been introduced. Therefore, usage of compact bidirectional converters were utilized more for such low voltage, low power application. For high power converter systems, another four level converter with switched capacitors [2] was developed. In order to increase the magnitude of output voltages and reduce the input inductor sizes, a multilevel boost converter [3] with a control of differential flatness theory has been introduced. Nevertheless, to attain optimization and stabilization of whole converter system, a voltage balancing technique for electric vehicle charging through the three level DC-DC converter has been reported [4].This technique enhances the usage of ESS (Energy Storage System) and also reduces the hardware requirements of the system. In the same way, to enhance the energy management and improve the performance of three level converter, online management algorithms through fast meta-heuristic approach were used [5]. To eliminate the additional balancing circuit and neutral-point currents, an active dc power balance management (APBM) [6] has been introduced. In recent past, to improve the performance of ultra-capacitors and also to obtain fast charging, a hardswitched three level bidirectional converter was designed [7]. However, this converter achieves the better efficiency at high DC bus voltages and high output power. To avoid usage of the converters such as multilevel and galvanic isolated, a hybrid storage system is implemented with a series-parallel connection of three port converter [8]. However, this converter has minimized switching losses and ratings of the switching devices. Then researchers focused on reducing the number of semiconductors and efficiency to be increase in bidirectional converters for dual voltage automotive systems, which resulted in a hybrid switched capacitor BDC [9] topology with a combination of switched capacitors and conventional BDC. Therefore, this hybrid topology has reduced the current ripple in input inductor and improved efficiency over the existed ones.

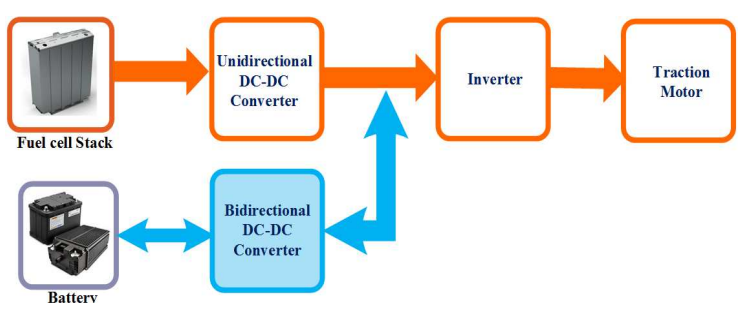

Fig.1 General structure of dual voltage automotive systems

BDCs with $360 \mathrm{~V} / 220 \mathrm{~V}$ [8] and $14 \mathrm{~V} / 42 \mathrm{~V}$ [10], are developed for dual voltage automotive systems to allow power flow to charge the battery and also to supply the required voltage to the inverter, when battery is in discharging mode. Fig. 1 shows the general structure of dual voltage automotive system.

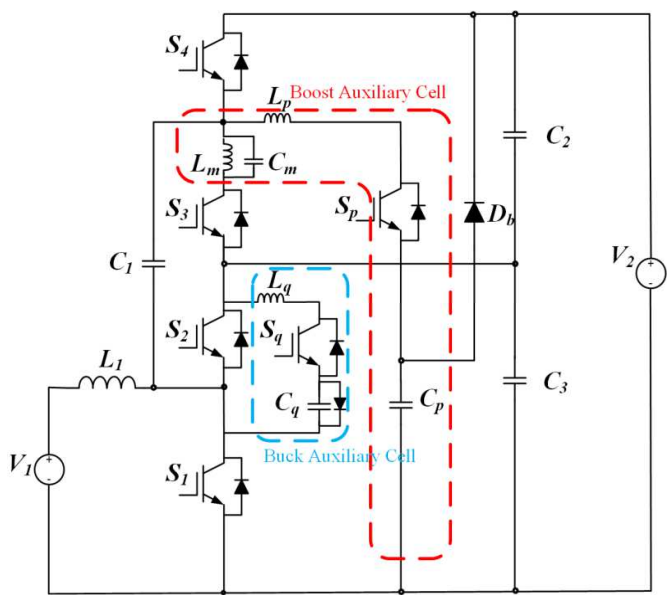

Fig.2 Proposed soft-switching bidirectional DC-DC converter

The additional feature, ZCS turn-on and ZCS turn-off conditions are achieved by utilizing two auxiliary cells in the proposed circuit, which work on wider voltage range unlike earlier versions. The switching losses and high power capability, are the main concern in the performance of the BDCs. Thus it is of interest to implement a new soft- 
switching BDC with minimized losses and improved efficiency. The main attention of this paper is to design a new soft-switching three level BDC for dual voltage automotive systems. The soft-switching for the semiconductors results in improving the efficiency and provide flexibility to operate at high output power.

\section{Proposed SOFT-SWITCHING BIDIRECTIONAL CONVERTER STRUCTURE AND ITS OPERATION}

The proposed converter structure is illustrated in Fig.2, which comprises of four IGBTs $S_{1}, S_{2}, S_{3}, S_{4}$ which are the main switching devices, three capacitors $C_{1}, C_{2}, C_{3}$ and one inductor $L_{1}$. In addition to main converter devices, two auxiliary resonant networks are added to the conventional hard-switched BDCs [8] [10]. These auxiliary networks are named as boost and buck auxiliary cells. Auxiliary resonant network consists of two IGBTs $S_{p}, S_{q}$, two resonant inductors $L_{p}, L_{q}$ and two capacitors $C_{p}, C_{q}$. In boost mode operation, the boost auxiliary cell provides soft-switching for the main switching devices. Similarly, in buck mode operation, the buck auxiliary cell provides soft-switching for the main switching devices. .

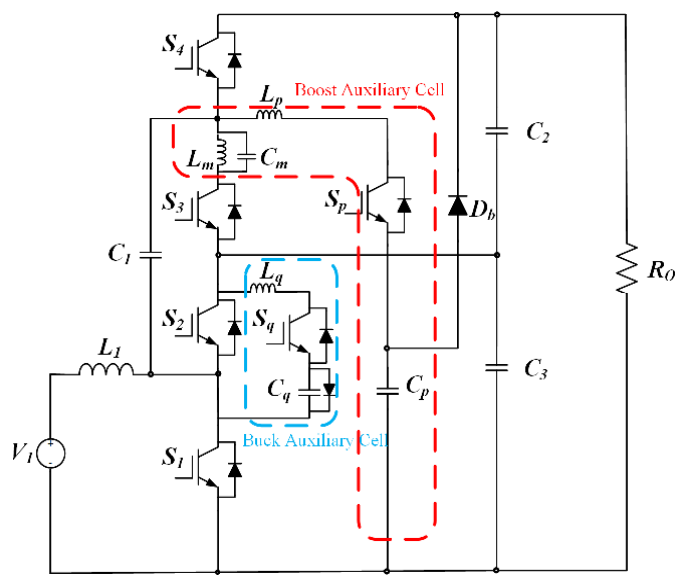

Fig.3 Equivalent schematic : Boost mode

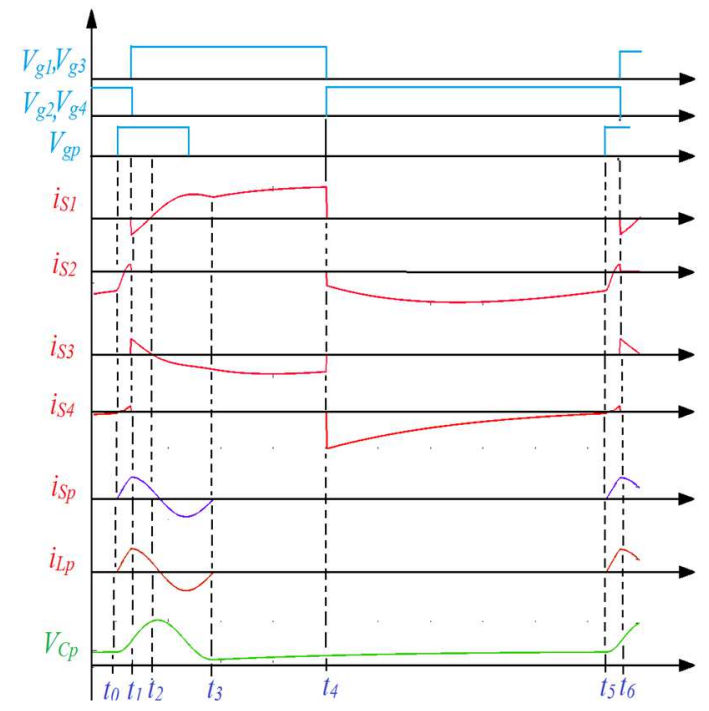

Fig.4 Key waveforms : Boost mode

Equivalent circuits for boost and buck modes are illustrated in Fig.3 and Fig.6. Operation of boost mode are divided into six modes for time intervals $t_{0}-t_{6}$ with the help of key waveform shown in Fig.4. Fig.5 (a, b, c, d, e) shows the boost mode equivalent current flow schematics of operating modes for time intervals $t_{0}-t_{5}$.
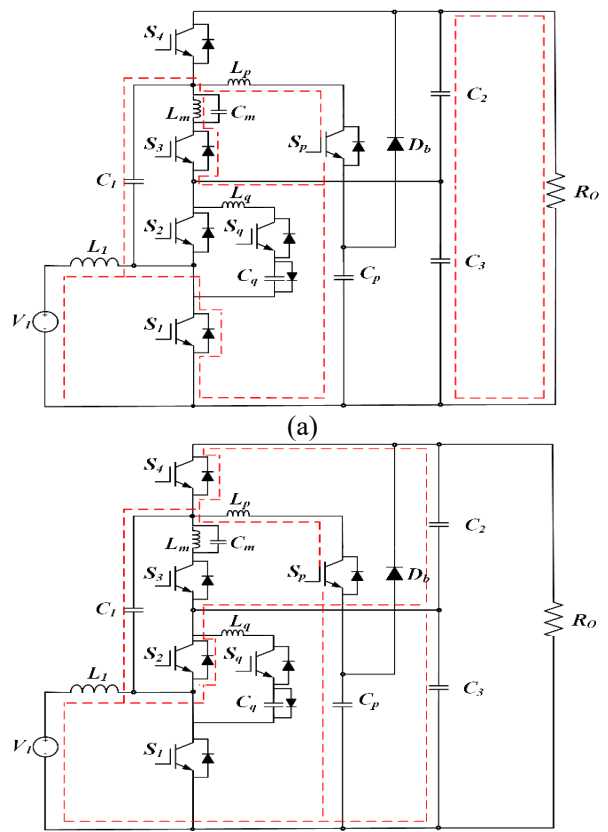

(b)

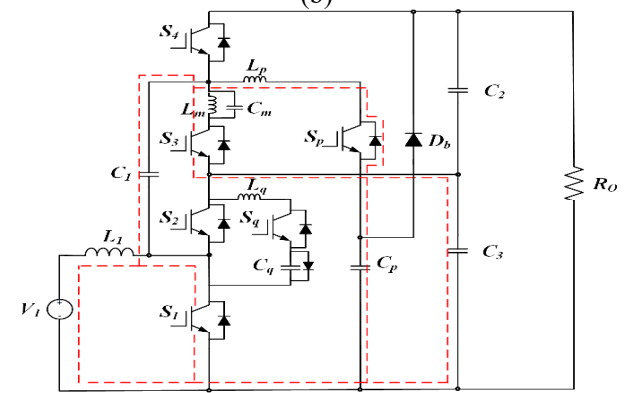

(c)

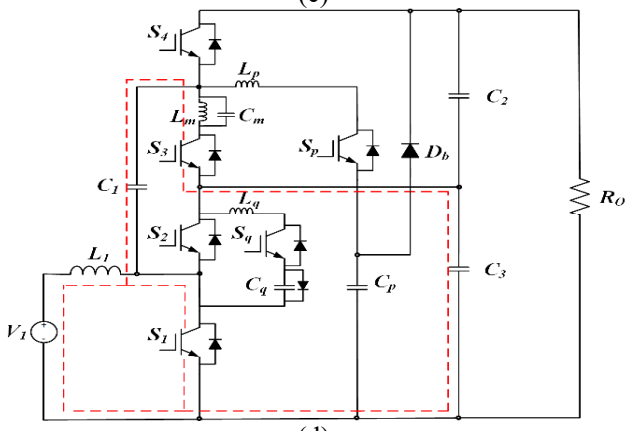

(d)

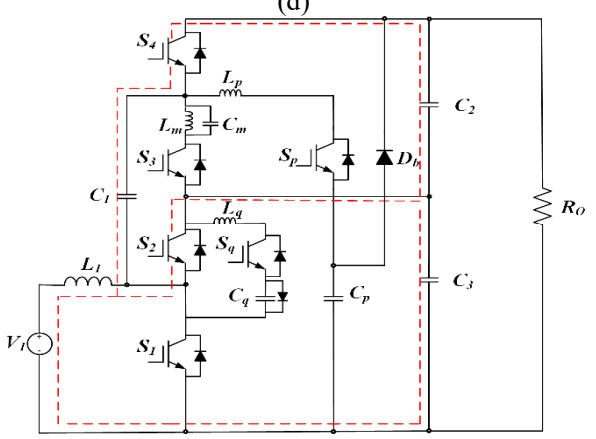

(e)

Fig.5 Operating modes (a) Interval $\left(t_{0}-t_{1}\right)(b)$ Interval $\left(t_{1}-t_{2}\right)(c)$ Interval $\left(t_{2}-t_{3}\right)$ (d) Interval $\left(\mathrm{t}_{3}-\mathrm{t}_{4}\right)(\mathrm{e})$ Interval $\left(\mathrm{t}_{4}-\mathrm{t}_{5}\right)$ :Boost mode 


\section{A. Boost mode operation}

At the beginning of this interval $\mathrm{t}_{0}$, the auxiliary IGBT $S_{p}$ is turned on and prior to $t_{0}, S_{2}, S_{4}$ are already in conducting state. $L_{p}$ and $C_{p}$ are resonating with each other, $L_{p}$ current increases linearly and $C_{p}$ charges to the level of input voltage. The current through the $S_{p}$ increases from zero, since the ZCS turn on operation is achieved. The current through the $S_{2}, S_{4}$ falls to zero and after half of this interval, their body diodes conduct to allow resonant current. Therefore, the ZCS turn off operation is obtained.

At time $\mathrm{t}_{1}$, the IGBTs $S_{1}, S_{3}$ are turned on, $L_{p}$ current starts reducing and $C_{p}$ discharges. This resonant current flows through the body diodes of $S_{1}, S_{3}$ until $t_{2}$. Hence, ZCS turn on is achieved in $S_{1}, S_{3}$. At $t_{1}$, the $S_{p}$ current is reaches zero. At $\mathrm{t}_{2}, S_{1}, S_{3}$ are turned on, a resonant peak current flows through the IGBTs $S_{l}$ and body diode of $S_{p}$ starts conducting. During $\mathrm{t}_{2}-\mathrm{t}_{3}$ interval, the output power delivers via $L_{1}-C_{1^{-}} S_{3^{-}}$ $C_{3}-R_{0}-C_{2}-S_{1}$. During the interval $\mathrm{t}_{3}-\mathrm{t}_{4}, S_{1}, S_{3}$ are in conduction state and the output power is delivered via $L_{1}-C_{1}-S_{3}-C_{2}-R_{o}-C_{3}$. At $t_{4}, I G B T_{s} S_{2}, S_{4}$ are turned on and the output power flow through $C_{1}-S_{4}-R_{0}-C_{3}-S_{2}$. From $\mathrm{t}_{5}-\mathrm{t}_{6}$, repeats the operation same as interval $\mathrm{t}_{0}-\mathrm{t}_{1}$.

\section{B. Buck mode operation}

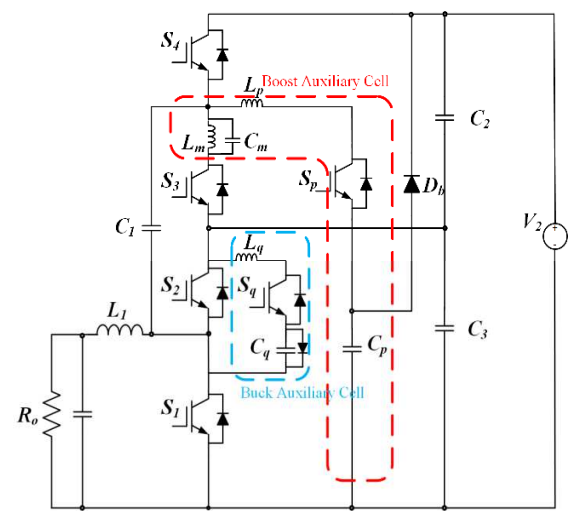

Fig.6 Equivalent schematic : Buck mode

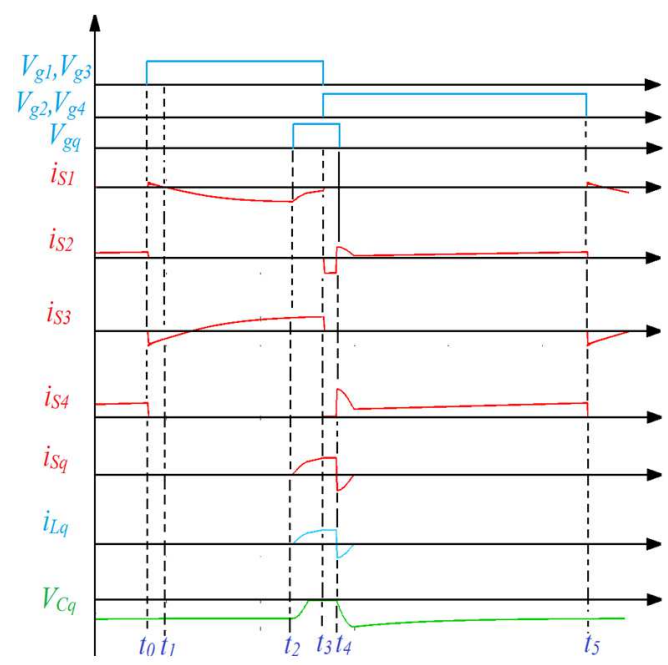

Fig.7 Key waveforms: Buck mode

Fig.6 shows the equivalent schematic of buck mode. The buck mode operation is similar to that of boost mode except for the direction of power flow. In this mode, the buck auxiliary cell is used to obtain soft-switching operation to the main switching devices. Operation of this mode is described with the help key waveform shown in Fig.7. At $t_{0}$, $S_{1} S_{3}$ are turned on. The voltage across these IGBTs reaches zero and their body diodes start conducting. Hence ZVS operation is achieved for IGBTs $S_{1}$ and $S_{3}$. At $\mathrm{t}_{1}$, body diodes of IGBTs $S_{l}, S_{3}$ stops conducting. During $\mathrm{t}_{1}-\mathrm{t}_{2}$ interval, $S_{1}, S_{3}$ are in conduction state. At $\mathrm{t}_{2}$, the auxiliary IGBT $S_{q}$ is turned on to provide soft turn-on for $S_{2}, S_{4}$ and $C_{q}$ is already charged to $-2 V_{2}$. From $\mathrm{t}_{2}, C_{q}$ starts discharging and $L_{q}$ current linearly increases to the level of output current. Due to resonance between $L_{q}, C_{q}$, the voltage across $S_{2}, S_{4}$ reduces to zero and current through $S_{1}$ reduces to zero. Therefore ZVS turn-on is achieved for $S_{2}, S_{4}$ and ZCS turn off operation is obtained for $S_{l}$. At the end $t_{3}$, the $C_{q}$ is completely discharged and $L_{q}$ current reaches to output current level. At $\mathrm{t}_{3}$, IGBTs $S_{2}, S_{4}$ are turned on, the body diode of $S_{2}$ starts conducting and $S_{4}$ current is still zero. At $\mathrm{t}_{4}$, $S_{q}$ is turned off and body diode of $S_{2}$ stops conducting. At $t_{4}$, the body diode of $S_{q}$, starts conducting, $C_{q}$ is charging, and $L_{q}$ current starts decreasing. At $\mathrm{t}_{5}, C_{q}$ is charged to $-2 V_{2}$ and $L_{q}$ current is reduced to zero. During $\mathrm{t}_{5}-\mathrm{t}_{6}$ interval, $S_{2}, S_{4}$ are turned on. The output power delivers via $V_{2}-S_{4-} C_{1}-L_{1}-R_{0}-C_{3-}$ $S_{3}$.

\section{Simulation RESUltS}

The proposed converter is designed by using MATLAB Simulink and its simulation results are presented in this section. The design simulation parameters of this converter are Boost mode input voltage $V_{l}: 100 \mathrm{~V}$, Buck mode input voltage $V_{2}: 350 \mathrm{~V}$,switching frequency : $75 \mathrm{kHz}$, Output power : $500 \mathrm{~W}, L_{1}: 100 \mu \mathrm{H}, C_{l}, C_{2}, C_{3}: 470 \mu \mathrm{F}, C_{p}, C_{q}: 5 \mathrm{nF}$ and $L_{p}, L_{q}: 25 \mu \mathrm{H}$.

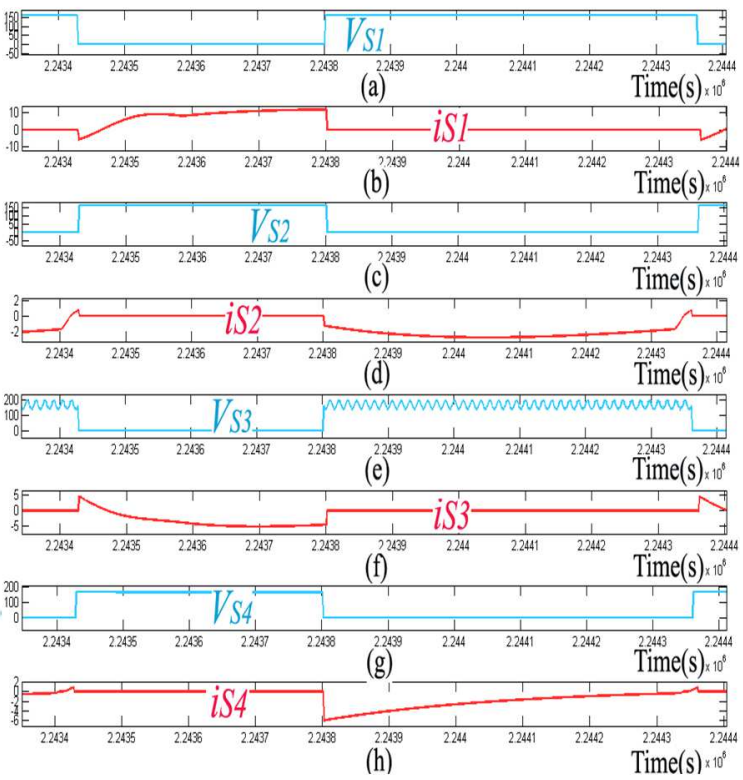

Fig. 8 Simulated Results: collector-emitter voltage and collector current waveforms: Boost mode (a) $V_{S I}$ (b) $i_{S 1}$ (c) $V_{S 2}$ (d) $i_{S 2}$ (e) $V_{S 3}$ (f) $i_{S 3}$ (g) $V_{S 4}$ (h) $i_{S 4}$

Fig.8 (a, b, c, d, e, f, g, h) shows the voltage and current waveforms of the IGBTs $S_{1}, S_{2}, S_{3}, S_{4}$. It can be seen from the obtained boost mode results, that the zero current switching (ZCS) turn-on operation for IGBTs $S_{1}, S_{3}$ and ZCS turn-off operation for $S_{2}, S_{4}$ are achieved. The current 
and voltage waveforms of $S_{p}, L_{p}, C_{p}$ illustrated in Fig.9 (a, b, c, d).It is observed from the obtained results, the auxiliary switch $S_{p}$ is turned-on and turned-off with ZCS condition. Similarly, simulations are carried out for buck mode operation. Fig.10 (a, b, c, d, e, f, g, h) shows the voltage and current waveforms of the IGBTs $S_{1}, S_{2}, S_{3}, S_{4}$. It is observed from these results, that the ZVS turn-on operation is obtained for $S_{1}, S_{2}, S_{3}, S_{4}$, IGBTs. The auxiliary switch $S_{q}$ is turned-on and turned-off with ZCS. Fig.11 (a, b, c, d) depicts the current and voltage waveforms of $S_{q}, L_{q}, C_{q}$. The auxiliary switch $S_{q}$ is turned-on and turned-off with ZCS.

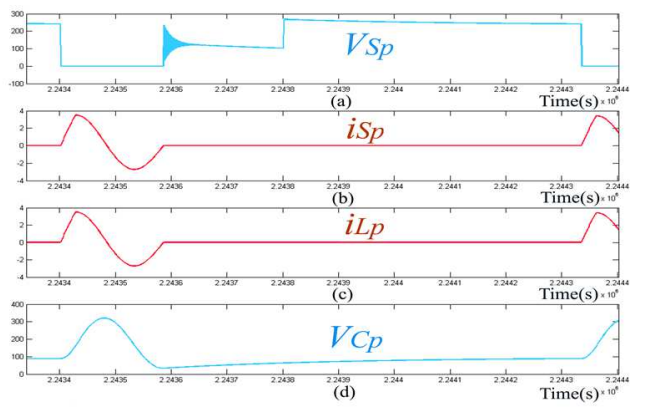

Fig.9. Simulated Results : Boost mode (a) $V_{S p}$ (b) $i_{S p}$ (c) $i_{L p}$ (d) $V_{C p}$

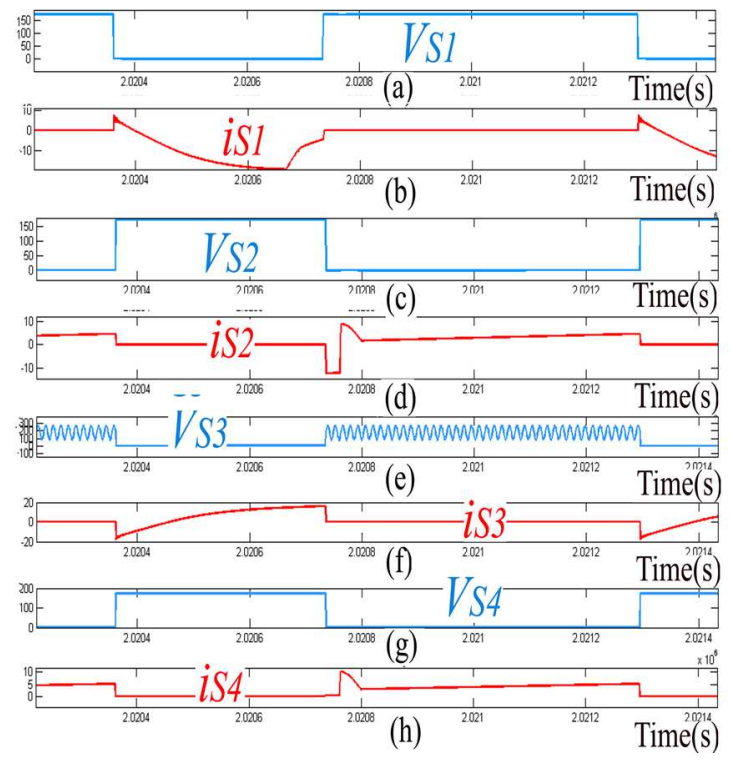

Fig.10 Simulated Results: collector-emitter voltage and collector current waveforms : Buck mode (a) $V_{S 1}$ (b) $i_{S 1}$ (c) $V_{S 2}$ (d) $i_{S 2}$ (e) $V_{S 3}$ (f) $i_{S 3}$ (g) $V_{S 4}$ (h) $i_{S 4}$

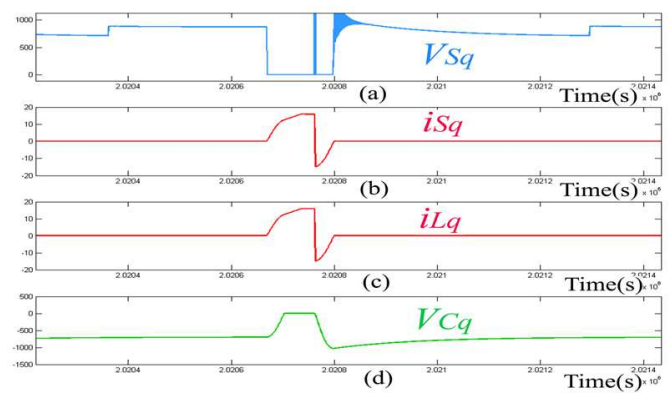

Fig.11. Simulated Results: Buck mode (a) $V_{S q}$ (b) $i_{S q}$ (c) $i_{L q}$ (d) $V_{C q}$

\section{CONCLUSION}

This paper proposes a new soft-switched bidirectional converter for battery storage applications in electric vehicles. The principles and simulation results are also discussed. The ZCS/ZVS turn-on is achieved in both the operating modes of boost and buck, respectively. The main advantages of this topology, especially when it is operating in boost mode, the main IGBTs and auxiliary IGBTs are soft turned-on and soft turned-off. While this converter is operating in buck mode, soft-turn-on of the main switch is achieved. The major advantage is that minimal reverse current flows through the diode of the main IGBTs. The simulation results verifies the theoretical analysis. Experimental analysis will be presented in next article. This proposed converter can be used for high power energy storage systems with reduced switching losses and improved efficiency.

\section{ACKNOWLEDGEMENT(S)}

This research has been supported by the Ministry of Education, Youth, and Sports of the Czech Republic under the project OP VVV Electrical Engineering Technologies with High-Level of Embedded Intelligence CZ.02.1.01/0.0/0.0/18_069/0009855 and project No. SGS-2021-021.

\section{REFERENCES}

[1] Fang Zheng Peng, Fan Zhang and Zhaoming Qian, "A magnetic-less DC-DC converter for dual-voltage automotive systems," in IEEE Transactions on Industry Applications, vol. 39, no. 2, pp. 511-518, March-April 2003.

[2] F. Zhang, L. Du, F. Z. Peng and Z. Qian, "A New Design Method for High-Power High-Efficiency Switched-Capacitor DC-DC Converters," IEEE Transactions on Power Electronics, vol. 23, no. 2, pp. 832-840, March 2008.

[3] P. Thounthong, "Control of a Three-Level Boost Converter Based on a Differential Flatness Approach for Fuel Cell Vehicle Applications," IEEE Transactions on Vehicular Technology, vol. 61, no. 3, pp. 14671472, March 2012.

[4] S. Rivera and B. Wu, "Electric Vehicle Charging Station With an Energy Storage Stage for Split-DC Bus Voltage Balancing," IEEE Transactions on Power Electronics, vol. 32, no. 3, pp. 2376-2386, March 2017.

[5] F. Machado, C. H. Antunes, M. R. Dubois and J. P. Trovao, "SemiActive Hybrid Topology with Three-Level DC-DC Converter for Electric Vehicle Application," 2015 IEEE Vehicle Power and Propulsion Conference (VPPC), Montreal, QC, 2015, pp. 1-6.

[6] L. Tan, B. Wu, S. Rivera and V. Yaramasu, "Comprehensive DC Power Balance Management in High-Power Three-Level DC-DC Converter for Electric Vehicle Fast Charging," IEEE Transactions on Power Electronics, vol. 31, no. 1, pp. 89-100, Jan. 2016.

[7] P. J. Grbovic, P. Delarue, P. Le Moigne and P. Bartholomeus, "A Bidirectional Three-Level DC-DC Converter for the Ultracapacitor Applications," IEEE Transactions on Industrial Electronics, vol. 57, no. 10, pp. 3415-3430, Oct. 2010.

[8] K. Jin, M. Yang, X. Ruan and M. Xu, "Three-Level Bidirectional Converter for Fuel-Cell/Battery Hybrid Power System," IEEE Transactions on Industrial Electronics, vol. 57, no. 6, pp. 1976-1986, June 2010.

[9] J. Garcia, R. Georgious, P. Garcia and A. Navarro-Rodriguez, "Nonisolated high-gain three-port converter for hybrid storage systems," 2016 IEEE Energy Conversion Congress and Exposition (ECCE), Milwaukee, WI, 2016, pp. 1-8.

[10] D. Flores Cortez, G. Waltrich, J. Fraigneaud, H. Miranda and I. Barbi, "DC-DC Converter for Dual-Voltage Automotive Systems Based on Bidirectional Hybrid Switched-Capacitor Architectures,"IEEE Transactions on Industrial Electronics, vol. 62, no. 5, pp. 3296-3304, May 2015. 